OPEN ACCESS

Edited by:

Haitao Shi,

Hainan University, China

Reviewed by:

Yongqiang Qian,

Chinese Academy of Forestry, China

Xunzhong Zhang,

Virginia Tech, USA

*Correspondence:

Liang Chen

chenliang1034@126.com

Jinmin Fu

jfu@wbgcas.cn

${ }^{\dagger}$ These authors have contributed equally to this work.

Specialty section

This article was submitted to

Plant Metabolism and Chemodiversity,

a section of the journal

Frontiers in Plant Science

Received: 13 September 2015

Accepted: 13 October 2015

Published: 03 November 2015

Citation:

Fan J, Hu Z, Xie Y, Chan Z, Chen K,

Amombo E, Chen L and Fu J (2015)

Alleviation of cold damage to

photosystem II and metabolisms by

melatonin in Bermudagrass.

Front. Plant Sci. 6:925

doi: $10.3389 /$ fpls.2015.00925

\section{Alleviation of cold damage to photosystem II and metabolisms by melatonin in Bermudagrass}

\author{
Jibiao Fan ${ }^{1,2+}$, Zhengrong Hu ${ }^{1,2+}$, Yan Xie ${ }^{1}$, Zhulong Chan ${ }^{1}$, Ke Chen ${ }^{1}$, Erick Amombo ${ }^{1,2}$, \\ Liang Chen ${ }^{1 *}$ and Jinmin $\mathrm{Fu}^{1 *}$ \\ ${ }^{1}$ Key Laboratory of Plant Germplasm Enhancement and Specialty Agriculture, Wuhan Botanical Garden, Chinese Academy \\ of Sciences, Wuhan, China, ${ }^{2}$ College of Life Sciences, University of Chinese Academy of Sciences, Beijing, China
}

As a typical warm-season grass, Bermudagrass [Cynodon dactylon (L).Pers.] is widely applied in turf systems and animal husbandry. However, cold temperature is a key factor limiting resource utilization for Bermudagrass. Therefore, it is relevant to study the mechanisms by which Burmudagrass responds to cold. Melatonin is a crucial animal and plant hormone that is responsible for plant abiotic stress responses. The objective of this study was to investigate the role of melatonin in cold stress response of Bermudagrass. Wild Bermudagrass pre-treated with $100 \mu \mathrm{M}$ melatonin was subjected to different cold stress treatments $\left(-5^{\circ} \mathrm{C}\right.$ for $8 \mathrm{~h}$ with or without cold acclimation). The results showed lower malondialdehyde (MDA) and electrolyte leakage (EL) values, higher levels of chlorophyll, and greater superoxide dismutase and peroxidase activities after melatonin treatment than those in non-melatonin treatment under cold stress. Analysis of chlorophyll a revealed that the chlorophyll fluorescence transient (OJIP) curves were higher after treatment with melatonin than that of non-melatonin treated plants under cold stress. The values of photosynthetic fluorescence parameters increased after treatment with melatonin under cold stress. The analysis of metabolism showed alterations in $\mathbf{4 6}$ metabolites in cold-stressed plants after melatonin treatment. Among the measured metabolites, five sugars (arabinose, mannose, glucopyranose, maltose, and turanose) and one organic acid (propanoic acid) were significantly increased. However, valine and threonic acid contents were reduced in melatonin-treated plants. In summary, melatonin maintained cell membrane stability, increased antioxidant enzymes activities, improved the process of photosystem II, and induced alterations in Bermudagrass metabolism under cold stress.

Keywords: melatonin, bermudagrass, cold stress, photosystem II, metabolism

\section{INTRODUCTION}

Bermudagrass [Cynodon dactylon (L).Pers.] is widely cultivated in sports fields, lawns and golf courses and used in animal husbandry. As a typical warm-season grass, the optimal temperature for growth ranges from 26.7 to $35^{\circ} \mathrm{C}$. When the temperature is below $15^{\circ} \mathrm{C}$, the plants stop growing. Hence, the utilization of Bermudagrass is limited by low temperature and the shoots wither in late autumn and winter. Thus, cold is considered as a key factor limiting widespread use in Bermudagrass. 
Cold stress can induce membrane damage to plants. Malonaldehyde (MDA) content and relative electrolyte leakage (EL) values were significantly increased after low temperature treatment (Zhang et al., 2006; Hou et al., 2010). Cold induces excessive production or inefficient deactivation of reactive oxygen species (ROS) such as hydrogen peroxide $\left(\mathrm{H}_{2} \mathrm{O}_{2}\right)$, hydroxyl radical $\left(\mathrm{OH}^{-}\right)$, and superoxide anion $\left(\mathrm{O}_{2^{-}}\right)$, thereby causing injury to plants (Monk et al., 1989). For self-protection against oxidative stress, plants have evolved efficient antioxidant systems to scavenge ROS (Allen, 1995). The activities of antioxidant enzymes such as superoxide dismutase (SOD), peroxidase (POD), and catalase (CAT) provide efficient protective mechanisms against oxidative stress (Baek and Skinner, 2003). The activities of these enzymes increased dramatically under cold stress (Hou et al., 2010; Ao et al., 2013).

Photosynthesis is a crucial plant metabolism process, which is extremely sensitive to cold stress. This is because low temperature disrupts almost all major components of photosynthesis (Allen and Ort, 2001; Dahal et al., 2012). In maize (Zea mays L.) and oats (Avena sativa L.), the efficiency of excitation capture by PSII reaction centers and the quantum yield of electron transport were higher in tolerant genotypes than that in sensitive varieties (Fracheboud et al., 1999; Rizza et al., 2001). The performance index and the chill factor index were higher in the tolerant genotypes of soybean [Glycine max (L.) Merr.] under chilling stress (Strauss et al., 2006).

Cold stress causes dramatic alterations in plant metabolism. Under cold stress, enzyme activities and reaction rates are generally reduced and the metabolome activity was reconfigured (Zhu et al., 2007). Metabolites such as sucrose, fructan, and proline were demonstrated to play protective roles in plants (Chen and Murata, 2002; Stitt and Hurry, 2002). Largescale profiling of metabolites by gas chromatography-mass spectrometry (GC-MS) has revealed extensive alterations in the plant metabolome in response to low temperature (Cook et al., 2004). The active reconfiguration of the metabolome depends on the changes of cold-responsive gene expression, which is regulated by cold signaling. Soluble sugars tetrapyrrole intermediate $\mathrm{Mg}$-protoporphyrin (Mg-ProtoIX), and ROS are three metabolic signals that might be crucial for cold signaling (Zhu et al., 2007).

Melatonin is a highly conserved molecule which functions as a hormone, protective antioxidant, and a mediator of circadian rhythms in both plants and animals (Murch and Saxena, 2002; Pelagio-Flores et al., 2012; Reiter et al., 2014). Dubbels et al. (1995) firstly detected melatonin in edible plants (Dubbels et al., 1995). Botanical studies of this hormone began with the discovery of abundant melatonin in the medicinal herbs, feverfew (Tanacetum parthenium) and St. John's wort (Hypericum perforatum) (Murch et al., 1997). More than 100 examined plant species contain melatonin (Chen et al., 2009).

Melatonin has a variety of functions in plants (Chen et al., 2009; Reiter et al., 2015). Melatonin behaves as an auxin which was involved in regulating root development in St. John's wort and hypocotyls growth in lupin (Lupinusalbus L.) (Murch et al., 2001; Hernández-Ruiz et al., 2004). Consistent with animals, melatonin concentrations change over a $24 \mathrm{~h}$ period, but the highest melatonin values may occur in the day (Tan et al., 2007) or at night (Kolár et al., 1997). As a free radical scavenger, melatonin protects plants from oxidative stress in all species tested (Manchester et al., 2000; Tal et al., 2011; Arnao and RuizHernandez, 2015; Reiter et al., 2015). Melatonin was also reported to modulate leaf senescence in Arabidopsis (Shi et al., 2015c) and it protects plants against abiotic stresses such as salinity, drought, heat and cold (Li et al., 2012; Bajwa et al., 2014; Meng et al., 2014; Shi et al., 2015d) and biotic stress (Lee et al., 2015; Zhao et al., 2015; Shi et al., 2015a).

Although, remarkable progress has been made in investigating melatonin involvement in abiotic stress response in recent years, studies on the effect of melatonin in Bermudagrass against cold stress have been rarely investigated. Recently, proteome and transcriptome analysis for Bermudagrass after melatonin treatment under salinity, drought, cold and $\mathrm{H}_{2} \mathrm{O}_{2}$ stress revealed that melatonin has protective roles in Bermudagrass response to abiotic stress (Shi et al., 2015b,e). In the present study, we employed physiological, photosynthetic, and metabolic methods to elucidate the possible mechanism of melatonin involved in the Bermudagrass response to cold stress. Our results revealed that melatonin contributes positively toward cold resistance of Bermudagrass by maintaining stability of cell membrane, and by modulating processes of photosynthesis and metabolism.

\section{MATERIALS AND METHODS}

\section{Plant Materials and Growth Conditions}

Bermudagrass [Cynodon dactylon (L).Pers.] used in this study was collected from wild field of Baise City, Guangxi Province, China $\left(\mathrm{N} 24^{\circ} 51.397\right.$, E $\left.106^{\circ} 33.288\right)$. To prepare the plant materials, stolons of Bermudagrass were planted in the plastic pots $(10 \mathrm{~cm}$ tall and $8 \mathrm{~cm}$ in diameter) that were filled with matrix (brown coal soil: silver sand $=1: 1$ ). Drainage holes were drilled at the bottom of the pots to avoid excessive water accumulation, and to ensure soil aeration. The pots that were planted with stolons were kept in a greenhouse with $12 \mathrm{~h}$ photoperiod, and day/night temperature was $30 / 25^{\circ} \mathrm{C}$ for around 1 month to establish the Bermudagrass plant. During Bermudagrass establishment, plants were watered with fullstrength Hoagland nutrient solution well (Hoagland and Arnon, 1950) every other day, until the liquid drained freely from drain holes.

\section{Treatments}

The established grass was transferred into the growth chamber with $12 \mathrm{~h}$ photoperiod and $30 / 25^{\circ} \mathrm{C}$ (day/night) temperature. Bermudagrass plants were subjected to six regimes: normal temperature (NT), cold acclimation (CA), non-cold acclimation (NA), normal temperature plus melatonin (NT+MLT), cold acclimation plus melatonin (CA+MLT), and non-cold acclimation plus melatonin (NA+MLT). For the control, plants were irrigated with pure water and maintained in the temperature of $30 / 25^{\circ} \mathrm{C}$ (day/night) until the experiment ended. For melatonin treatment, plants were pretreated with $100 \mu \mathrm{M}$ melatonin solution for $7 \mathrm{~d}$. After pre-treatment, the 
plants were subjected to cold stress. For cold stress treatment, cold acclimation (CA), and non-cold acclimation (NA) were designed. For CA treatment, Bermudagrass plants were treated with $4^{\circ} \mathrm{C}$ for $7 \mathrm{~d}$, and then transferred to $-5^{\circ} \mathrm{C}$ for $8 \mathrm{~h}$. For NA treatment, the Bermudagrass were treated with $-5^{\circ} \mathrm{C}$ for $8 \mathrm{~h}$ without pre-treatment with $4^{\circ} \mathrm{C}$. The plants that were treated with freezing stress were recovered at $4^{\circ} \mathrm{C}$ overnight and then transferred to $30^{\circ} \mathrm{C}$ for $1 \mathrm{~d}$. Appropriate temperature for Bermudagrass growth $\left(30^{\circ} \mathrm{C}\right)$ was used for control. Five pots with around 50 plants each were applied for each treatment.

\section{Crude Enzyme Extraction}

$0.2 \mathrm{~g}$ of fresh leaves were ground into fine powder with liquid nitrogen. $4 \mathrm{~mL}$ of $150 \mathrm{mM}$, pH 7.0 sodium phosphate buffer (precooled at $4^{\circ} \mathrm{C}$ ) was added into the powder. Then the homogenate was transferred into $10 \mathrm{~mL}$ centrifuge tube, and centrifuged with $13400 \mathrm{~g}$ at $4^{\circ} \mathrm{C}$ for $20 \mathrm{~min}$. The supernatant was the crude enzyme solution that to be determined.

\section{Determination of Malonaldehyde (MDA) Content}

MDA content was determined by thiobarbituric acid (TBA) method according to previous study (Hu et al., 2012; Fan et al., 2014). A $1 \mathrm{~mL}$ of crude enzyme solution was added into $2 \mathrm{~mL}$ MDA reaction buffer that included $0.5 \%(\mathrm{v} / \mathrm{v})$ thiobarbituric acid (TBA) and $20 \%(\mathrm{v} / \mathrm{v})$ trichloroacetic acid. The reaction solution was heated at $95^{\circ} \mathrm{C}$ for $30 \mathrm{~min}$ in a water bath, then cooled to room temperature $\left(25^{\circ} \mathrm{C}\right)$ and centrifuged at $12000 \mathrm{rpm}$ at $25^{\circ} \mathrm{C}$ for $10 \mathrm{~min}$. The supernatant was determined for absorbance at $532 \mathrm{~nm}$ and $600 \mathrm{~nm}$ with a spectrophotometer. MDA content was calculated with following formula:

$\operatorname{MDA}\left(\mathrm{molg}^{-1} \mathrm{FW}\right)=[(\mathrm{OD} 532-\mathrm{OD} 600) \times \mathrm{L}] /(1 \times \varepsilon \times \mathrm{FW})$.

Where $\mathrm{L}$ indicates the volume of the extract solution, 1 indicates thickness of the cuvettes, $\varepsilon$ represents the molar absorption coefficient of $155 \mathrm{mM}^{-1} \mathrm{~cm}^{-1}$, and $\mathrm{FW}$ is the fresh weight of the leaf.

\section{Quantification of Electrolyte Leakage (EL)}

To quantify relative EL, $0.1 \mathrm{~g}$ of fully expanded leaves were collected from the plants and washed three times with deionized water. The leaves were cut into $0.5 \mathrm{~cm}$ fragments and transferred into $50 \mathrm{~mL}$ centrifuge tube filled with $15 \mathrm{~mL}$ deionized water. The tube-fragments systems were shaken for $24 \mathrm{~h}$ at room temperature and the initial conductivity $\left(\mathrm{EL}_{1}\right)$ was measured with a conductance meter (JENCO). Then, the leaf tissue in the tube was autoclaved at $121^{\circ} \mathrm{C}$ for $10 \mathrm{~min}$ to release the electrolytes completely. The final conductivity $\left(\mathrm{EL}_{2}\right)$ was measured after cooling the solution at room temperature. The relative EL was calculated by the formula:

$$
\text { Relative } \mathrm{EL}=\mathrm{EL}_{1} / \mathrm{EL}_{2} \times 100 \% .
$$

\section{Quantification of Melatonin}

Quantification of plant melatonin was performed with enzymelinked immunosorbent assay (ELISA) method. Briefly, $0.3 \mathrm{~g}$ of leaf tissues was ground into fine powder in liquid nitrogen. Then the powder was transferred to the tube containing $5 \mathrm{ml}$ of extraction solution (acetone:methanol:water $=89: 10: 1$ )and homogenized on ice for $1 \mathrm{~h}$. After that the homogenate was centrifuged at $4^{\circ} \mathrm{C}$ for $5 \mathrm{~min}$ at $4500 \mathrm{~g}$. The supernatant was transferred to a new tube and mixed with $0.5 \mathrm{ml}$ of $1 \%$ trichloric acid. Then the mixture was centrifuged at $4^{\circ} \mathrm{C}$ for $10 \mathrm{~min}$ at $4500 \mathrm{~g}$, the extract was used to determine the melatonin content with Melatonin ELISA Kit (EK-DSM; Buhlmann LaboratoriesAG, Schonenbuch, Switzerland) according to the manufacturer instruction.

\section{Determination of Antioxidants}

To determine SOD activity, $1 \mathrm{~mL}$ of crude enzyme solution was mixed into $3 \mathrm{~mL}$ solution which include $2.2 \mathrm{~mL}$ sodium phosphate buffer (50 mM, pH 7.8), $0.039 \mathrm{mM}$ methionine, $0.3 \mathrm{nM}$ ethylene diaminetetraacetic acid (EDTA), $0.012 \mu \mathrm{M}$ riboflavin, and $0.225 \mu \mathrm{M}$ nitro blue tetrazolium (NBT). $3 \mathrm{~mL}$ reaction mixture with no crude enzyme solution was set as control. For chromogenic reaction, the mixture was illuminated under 4000 lx fluorescent lamp for $60 \mathrm{~min}$. The absorbance at $560 \mathrm{~nm}$ was measured with a spectrophotometer. One unit of SOD activity was defined as amount of SOD required to inhibit NBT reduction by $50 \%$.

To determine POD activity, $50 \mu \mathrm{L}$ of crude enzyme solution was added into $2.95 \mathrm{~mL}$ reaction solution which include $1.85 \mathrm{~mL}$, sodium acetate-acetic acid buffer $(\mathrm{pH} 5.0), 0.25 \mathrm{~mL}$ guaiacol (dissolved in 50\% ethanol solution), and $0.075 \mathrm{~mL} \mathrm{H}_{2} \mathrm{O}_{2}$. Absorbance increase per minute at $460 \mathrm{~nm}$ was recorded for 3 min. Increment of 1 unit of the absorbance per minute was defined as one unit POD activity.

\section{Quantifications of Chlorophyll Content}

Leaf chlorophyll content was determined by the method that described by Hiscox and Israelstam (1979) with slight modification. In detail, $0.1 \mathrm{~g}$ of leaf samples was submerged into $10 \mathrm{~mL}$ dimethylsulfoxide that was contained in $15 \mathrm{~mL}$ centrifuge tubes. Then the tubes which contained the leaves were kept in the dark for $48 \mathrm{~h}$. Absorbance at $645 \mathrm{~nm}$ and $663 \mathrm{~nm}$ of the extract solution were measured with a spectrophotometer. Chlorophyll content was calculated with the following formula:

$$
\mathrm{Chl}-\operatorname{content}\left(\mathrm{mg} \cdot \mathrm{L}^{-1}\right)=20.2 \times \mathrm{OD} 645+8.02 \times \text { OD663. }
$$

OD645 and OD663 indicate the absorbance of the extract solution at $645 \mathrm{~nm}$ and $663 \mathrm{~nm}$, respectively.

\section{Measurement of Chlorophyll a Fluorescence (OJIP) Kinetics}

Chlorophyll fluorescence was determined with a pulse-amplitude modulation (PAM) portable chlorophyll fluorometer PAM2500. The plants were pre-adapted in dark for $30 \mathrm{~min}$ before measurement to ensure sufficient closure of all PSII reaction centers and estimate the maximum fluorescence yield. The OJIP transients were detected by the measuring light of $3000 \mu \mathrm{mol}$ photons $\mathrm{m}^{-2} \mathrm{~s}^{-1}$. The Chla fluorescence emission induced by the strong light pulses was determined and digitized between $10 \mu \mathrm{s}$ 
and $320 \mathrm{~ms}$. JIP-test was applied to analyze the OJIP curve. The measurement was conducted at room temperature. To avoid the affection by temperature jump, the determination was performed immediately when the plants were took out of the chamber.

\section{Extraction, Derivation and Quantification of Metabolites}

$0.15 \mathrm{~g}$ of fully expanded leaves were collected from Bermudagrass plant after treatments, and frozen in liquid nitrogen immediately then stored at $-80^{\circ} \mathrm{C}$ until for analysis. Metabolite extraction was done according to the method described by Xie et al. (2014). The frozen leaves were grounded into fine powder with liquid nitrogen, and then the powders were transferred to $2 \mathrm{~mL}$ microcentrifuge tubes that containing $1.4 \mathrm{~mL}$ of $80 \%$ $(\mathrm{v} / \mathrm{v})$ aqueous methanol. After that, the tubes were shaken at $200 \mathrm{rpm}$ for $2 \mathrm{~h}$ at room temperature $\left(25^{\circ} \mathrm{C}\right)$ in the shaker. $50 \mu \mathrm{L}$ ribitol solutions $\left(2 \mathrm{mg} \mathrm{mL}^{-1}\right)$ were added as an internal standard. The mixture was incubated in a water bath at $70^{\circ} \mathrm{C}$ for $15 \mathrm{~min}$ and centrifuged at $12000 \mathrm{rpm}$ for $10 \mathrm{~min}$. The supernatant was transferred to new $10 \mathrm{~mL}$ tubes with $1.5 \mathrm{~mL}$ of water and $0.75 \mathrm{~mL}$ of chloroform was added. The mixture was vortex shocked thoroughly for $15 \mathrm{~s}$ and centrifuged at $13400 \mathrm{~g}$ for $10 \mathrm{~min} .0 .3 \mathrm{~mL}$ of the polar phase was transferred into $2 \mathrm{~mL}$ HPLC vials and dried in a centrifugal concentrator (Labogene, Denmark) overnight. The dried polar phase was derivatized with $80 \mu \mathrm{L}$ of $20 \mathrm{mg} \mathrm{mL}^{-1}$ methoxyamine hydrochloride in pyridine at $30^{\circ} \mathrm{C}$ for $2 \mathrm{~h}$, and trimethylsilylated with $50 \mu \mathrm{L} \mathrm{N}$-methyl- $N$ trimethylsilyltrifluoroacetamide (MSTFA) at $37^{\circ} \mathrm{C}$ for $2 \mathrm{~h}$. The reagents used in this study were purchased from Sigma-Aldrich Co. Ltd. (Poole, UK).

The metabolites were determined with GC-MS (Agilent 7890A/5975C, Agilent Technologies, Palo Alto, CA, USA) as described by Xie et al. (2014). For GC-MS operation, $1 \mu \mathrm{L}$ of derivatizated sample was added into a DB-5MS capillary $(30 \mathrm{~m} \times$ $0.25 \mathrm{~mm} \times 0.25 \mathrm{~mm}$, Agilent J\&W GC column, USA). The inlet temperature was set at $280^{\circ} \mathrm{C}$ and after a solvent delay for $5 \mathrm{~min}$; the initial gas chromatography (GC) oven temperature was set at $70^{\circ} \mathrm{C}$. After $1 \mathrm{~min}$ injection, the temperature of GC oven was raised $5^{\circ} \mathrm{C}$ per min until to $280^{\circ} \mathrm{C}$, and then held at $280^{\circ} \mathrm{C}$ for $10 \mathrm{~min}$. The injection temperature was set at $280^{\circ} \mathrm{C}$ and ion source temperature $\left(230^{\circ} \mathrm{C}\right)$ was matched simultaneously. Helium was applied as the carrier gas, and the constant flow rate was set at $1 \mathrm{~mL} \mathrm{~min}^{-1}$. Mass spectra were determined at 2 scans. $\mathrm{s}^{-1}$ with electron impact ionization $(70 \mathrm{eV})$ in the full scan mode $(m / z 30-650)$.

\section{Metabolite Data Processing and Analysis}

The metabolites were identified based on the retention time with software of Agilent MSD Productivity Chemstation and associated with the commercially available compound libraries (NIST 11) (Gaithersburg, MD, USA). Relative quantification of the metabolites was estimated based on the value of ribitol which was the internal standard. The principal component analysis (PCA) and hierarchical clustering analysis (HCA) were performed on the MetaboAnalyst webpage (http://www. metaboanalyst.ca/MetaboAnalyst/). Log-transformed response
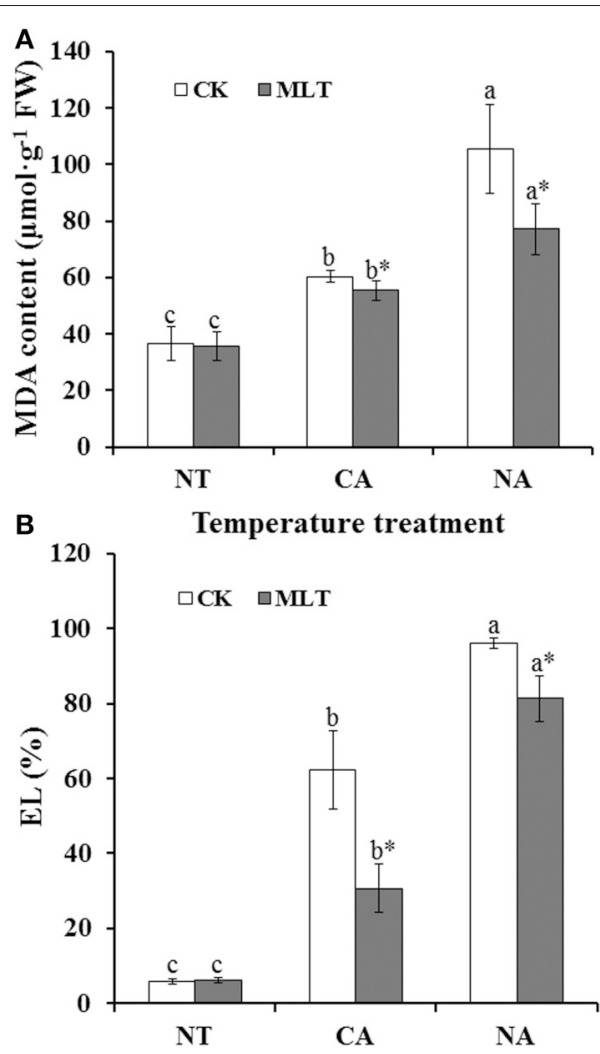

Temperature treatment

FIGURE 1 | Alteration of cell membrane stability and lipid peroxidation in the leaves of bermudagrass after $100 \mu \mathrm{M}$ melatonin treatment under cold stress. (A) Malonaldehyde (MDA) content; (B) electrolyte leakage (EL). Experiment included five repeats of each treatment, and means were average values of MDA content and EL, respectively. Independent-samples $t$-test was used to determine statistical differences. Bars show standard deviation. Columns marked with different letters indicate statistical difference significance at $P<0.05$ among the temperature treatments. Column marked with asterisk was significantly different after MLT treatment. NT was normal temperature of $30^{\circ} \mathrm{C}$. CA was cold acclimation, during which Bermudagrass was treated with $4^{\circ} \mathrm{C}$ for $7 \mathrm{~d}$ and then transferred to $-5^{\circ} \mathrm{C}$ for $8 \mathrm{~h}$. NA was cold stress without acclimation, in which plants were treated with $-5^{\circ} \mathrm{C}$ for $8 \mathrm{~h}$ without pre-treatment with $4^{\circ} \mathrm{C}$. CK was control (treated without melatonin). MLT, melatonin; FW, fresh weight.

ratios for each identified metabolites were calculated before statistical assessment.

\section{Statistical Analysis}

For metabolism analysis, each experiment was repeated for three times, and statistical analysis was performed by One-way analysis of variance (ANOVA). Means were separated with Duncan's multiple range tests at a significant level of $P<0.05$. For other data, the experiment was set five repeats of each treatment, independent-samples $t$-test was used to determine statistical differences. Standard deviations (SD) were used to show the data. The means are the average of the repeats. Bars with the letters above the columns of the figures indicate significant differences $(P<0.05)$. 


\section{RESULTS}

To investigate whether the exogenous melatonin played a positive role in maintaining cell membrane stability of Bermudagrass under cold stress, MDA content and EL alterations were determined. The results showed that, both MDA and EL were higher in the plants after cold treatment than those of control. Moreover, under cold stress, MDA and EL were higher in the regime of non-cold acclimation (NA) than those in regime of cold acclimation (CA) (Figure 1). However, in these two cold treatment regimes, MDA contents in plants treated with melatonin were $8.3 \%$ (CA regime) and $26.7 \%$ (NA regime) lower than that in the plants without melatonin treatment, respectively (Figure 1A). These results showed that exogenous melatonin protects the cell membrane against lipid peroxidation. Similar results were also observed regarding relative EL values. Relative EL in melatonin treatment plants were 50.8\% (CA regime) and $15.3 \%$ (NA regime) lower than those in the plants without melatonin treatment, respectively (Figure 1B). These results suggested that melatonin participated in maintaining cell membrane stability.

To investigate how the melatonin content changed in plant under cold stress after exogenous melatonin treatment, levels of endogenous melatonin in the leaves were determined after different treatments. The results showed that melatonin content increased dramatically after cold treatment. Endogenous melatonin increased significantly after the plant was treated with exogenous melatonin in CA and NA regimes (12.8 and 18.1\%,

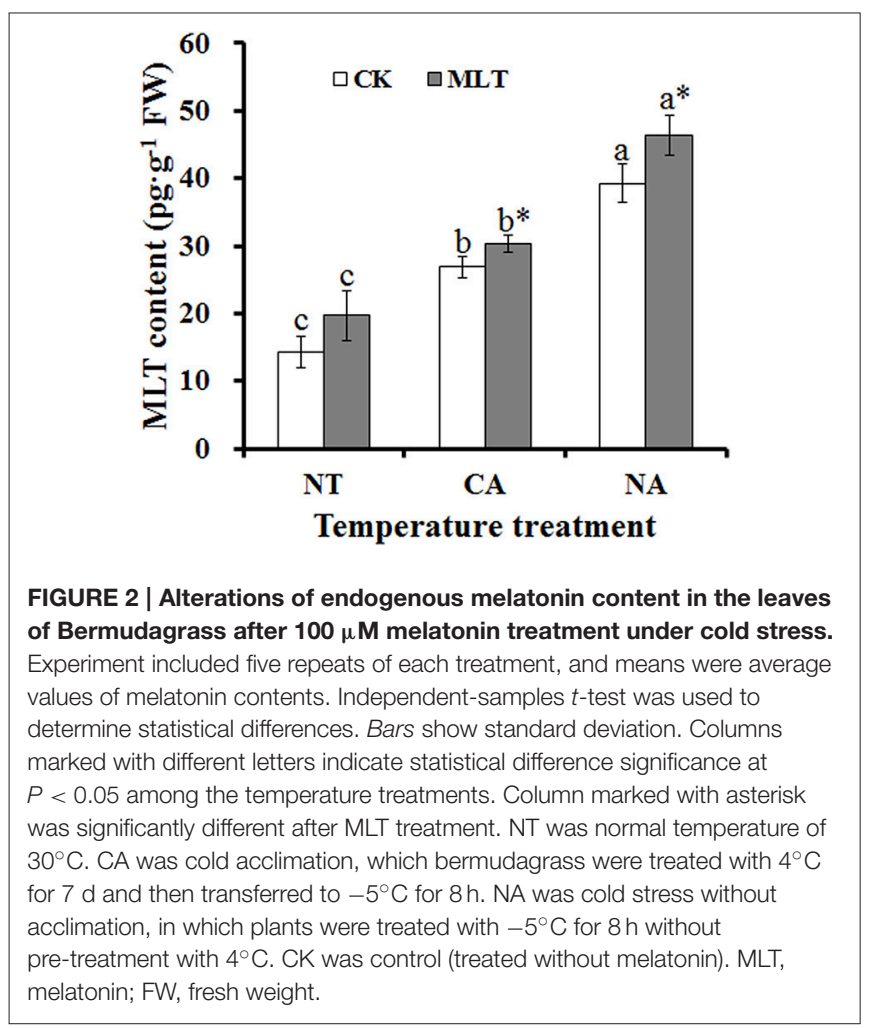

respectively) (Figure 2). These results suggested exogenous melatonin could affect the level of endogenous melatonin.

To investigate the effect of melatonin on antioxidant enzymes, activities of SOD and POD were determined. As shown in Figure 2, the antioxidant enzyme activities were increased in plants after cold treatment (NA and $\mathrm{CA}$ ) relative to control temperature $\left(30^{\circ} \mathrm{C}\right)$. As for melatonin treatment, there was no significant difference in melatonin pretreated plants compared with non-pretreated regimes under control conditions. However, when plants were subjected to cold stress, the SOD and POD activities increased significantly as a result of melatonin treatment. In CA and NA regimes, SOD activity was 17.3 and 9.1\% higher in the melatonin-treated plants than non-melatonin treatment regimes, respectively (Figure 3A). Similar results were

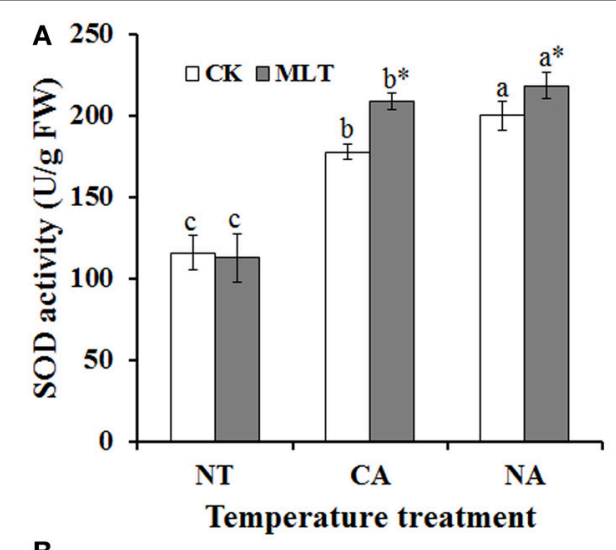

B

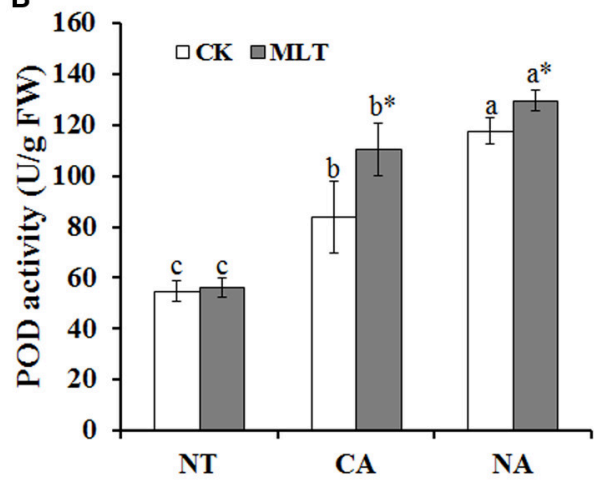

Temperature treatment

FIGURE 3 | Alterations of antioxidant enzyme activities in the leaves of Bermudagrass after $100 \mu \mathrm{M}$ melatonin treatment under cold stress. (A) Activity of superoxide dismutase (SOD); (B) Activity of peroxidase (POD). Experiment included five repeats of each treatment, and means were average values of activities of SOD and POD, respectively. Independent-samples $t$-test was used to determine statistical differences. Bars show standard deviation. Columns marked with different letters indicate statistical difference significance at $P<0.05$ among the temperature treatments. Column marked with asterisk was significantly different after MLT treatment. NT was normal temperature of $30^{\circ} \mathrm{C}$. CA was cold acclimation, which bermudagrass were treated with $4^{\circ} \mathrm{C}$ for $7 \mathrm{~d}$ and then transferred to $-5^{\circ} \mathrm{C}$ for $8 \mathrm{~h}$. NA was cold stress without acclimation, in which plants were treated with $-5^{\circ} \mathrm{C}$ for $8 \mathrm{~h}$ without pre-treatment with $4^{\circ} \mathrm{C}$. CK was control (treated without melatonin). MLT, melatonin; FW, fresh weight. 

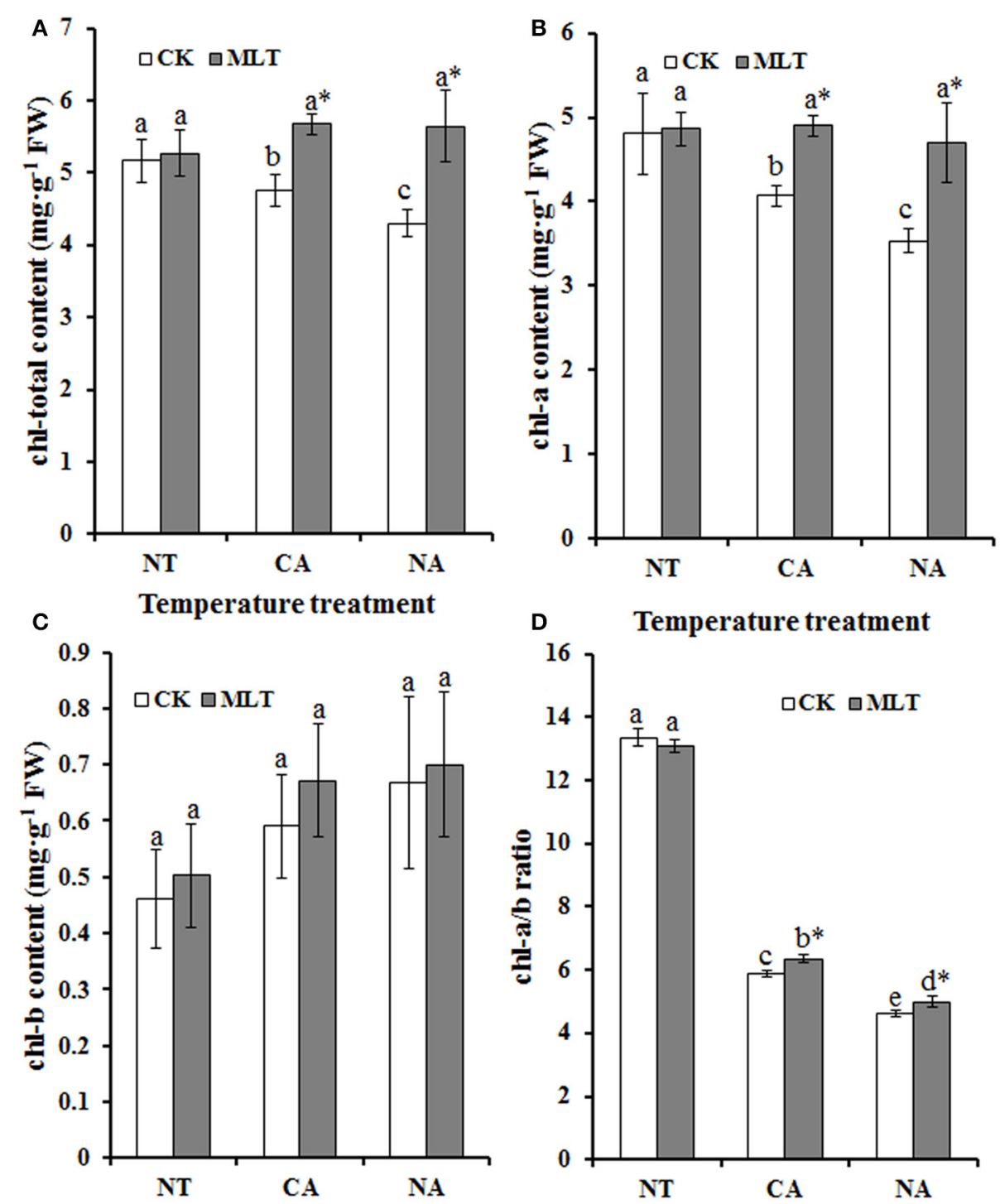

Temperature treatment
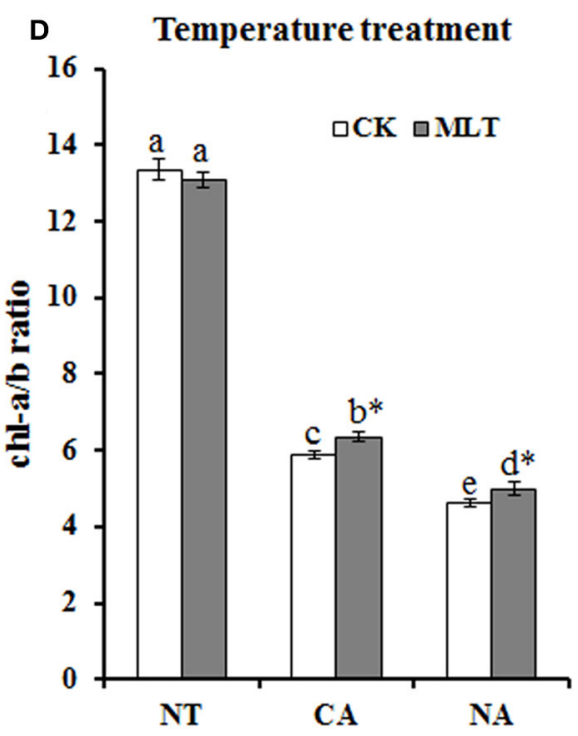

Temperature treatment

FIGURE 4 | Alteration of chlorophyll content of Bermudagrass after $100 \mu \mathrm{M}$ melatonin treatment under cold stress. (A) Total chlorophyll content; (B) chlorophyll a content; (C) chlorophyll b content; (D) ratio of chlorophyll a to b. Experiment included five repeats of each treatment, and means were average values of the data. Independent-samples $t$-test was used to determine statistical differences. Bars show standard deviation. Columns marked with different letters indicate statistical difference significance at $P<0.05$ among the temperature treatments. Column marked with asterisk was significantly different after MLT treatment. NT was normal temperature of $30^{\circ} \mathrm{C}$. CA was cold acclimation, which Bermudagrass were treated with $4^{\circ} \mathrm{C}$ for $7 \mathrm{~d}$ and then transferred to $-5^{\circ} \mathrm{C}$ for $8 \mathrm{~h}$. NA was cold stress without acclimation, in which plants were treated with $-5^{\circ} \mathrm{C}$ for $8 \mathrm{~h}$ without pre-treatment with $4^{\circ} \mathrm{C}$. CK was control (treated without melatonin). MLT, melatonin; FW, fresh weight.

also observed in POD activity. After melatonin treatment, the POD activity was $10.2 \%$ higher than non-melatonin treatment in NA regime. Additionally, the POD was as high as 1.3-fold compared with the plants without melatonin treatment in the CA regime (Figure 3B). These results document that melatonin plays essential roles in increasing antioxidant enzymes activities in Bermudagrass in response to cold stress.

There was chlorosis when plants were exposed to abiotic stress, and chlorophyll content was regarded as an indicator to reveal the stress resistance of plants. In this study, total chlorophyll content was measured. As shown in Figure 4, total chlorophyll content was higher in plants under control conditions than the cold- treated plants, and melatonin had no effect on the plants under control conditions. But after cold treatment, the total chlorophyll content was significantly higher in plants pretreated with exogenous melatonin than the untreated regimes. In both CA and NA regimes, total chlorophyll contents were $19.2 \%$ (CA regime) and $31.2 \%$ (NA regime) higher in 
the plants treated with melatonin than those without melatonin treatment, respectively (Figure $4 \mathrm{~A}$ ). The ratio of chlorophyll $a$ to $b(\mathrm{chl}-\mathrm{a} / \mathrm{b})$ was higher in the plants in the CA regime than those in the NA regime (Figure 4D). In addition, in each regime, the melatonin-treated plants had higher chl- $a / b$ compared to that non- melatonin treated plants (Figure 4D). These results showed that exogenous melatonin maintains chlorophyll stability of plants under cold stress, and thus likely improves cold resistance of the plants.

Since Bermudagrass (after melatonin pretreatment) had higher chlorophyll content under cold stress, we predicted that melatonin was involved in photosystem regulation. OJIP transient curves of the plants with different treatments were measured and the JIP test was analyzed. The results showed that OJIP transient curve in plants under control condition was higher than those under cold treatment. Furthermore, the plants treated with $-5^{\circ} \mathrm{C}$ after cold acclimation showed higher OJIP transient curve than plants treated with freezing temperatures

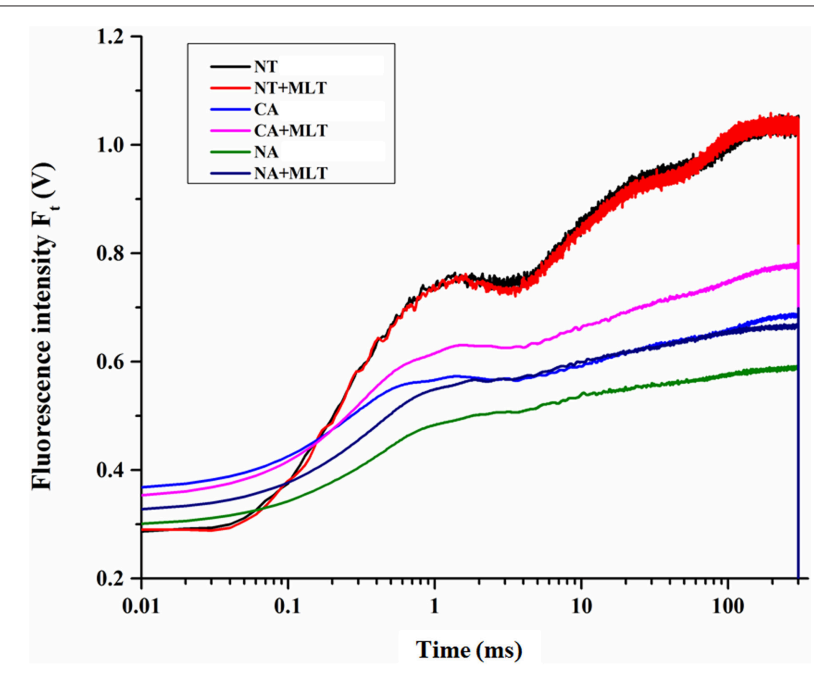

FIGURE 5 | Alterations of chlorophyll fluorescence transients (OJIP curve) in Bermudagrass leaves after $100 \mu \mathrm{M}$ melatonin treatment under cold stress. NT was normal temperature of $30^{\circ} \mathrm{C}$. CA was cold acclimation, in which bermudagrass were treated with $4^{\circ} \mathrm{C}$ for $7 \mathrm{~d}$ and then transferred to $-5^{\circ} \mathrm{C}$ for $8 \mathrm{~h}$. NA was cold stress without acclimation which plants were treated with $-5^{\circ} \mathrm{C}$ for $8 \mathrm{~h}$ without pre-treatment with $4^{\circ} \mathrm{C}$. MLT, melatonin. without cold acclimation. Moreover, in each regime under cold stress, the curves were higher in the plants given exogenous melatonin than those in plants without melatonin treatment (Figure 5). This confirms that cold acclimation and exogenous melatonin treatment dramatically affected the OJIP transient curves of Bermudagrass leaves under cold stress.

To further explore the effect of melatonin on PSII in Bermudagrass under cold stress, the JIP-test was applied to study the OJIP transient curves. Basic fluorescence parameters including $F_{0}, F_{\mathrm{K}}, F_{\mathrm{J}}, F_{\mathrm{I}}, F_{\mathrm{M}}$, and $M_{0}$ were extracted. As the result showed, the basic parameters were higher under control condition than under cold stress except for $F_{0}$ which was lower. Under cold stress, $F_{0}$ was higher in CA regime than that in NA regime, but there was no significant difference in the plants with or without melatonin treatment. However, the plants that were simultaneously treated with cold acclimation and melatonin had the highest values of $F_{M}$ and other parameters. Meanwhile, the plants that were neither treated with cold nor melatonin had the lowest values (Table 1).

JIP-test was used to analyze the basic fluorescence in order to determine the structural and functional parameters quantifying the photosynthetic behavior of the plants. The results showed significant differences between parameters under different treatments. Performance index $(\mathrm{PI}), \mathrm{PI}_{\text {total }}$, and $\mathrm{PI}_{\mathrm{ABS}}$, are important indexes to describe the overall activity of PSII. As shown in Figure 5, performance indexes (PI) were higher under control condition than that under cold stress. There was no significant difference between the plants with and without melatonin treatment. After cold treatment, the values of $\mathrm{PI}_{\text {total }}$ and $\mathrm{PI}_{\mathrm{ABS}}$ were higher in the plants after cold acclimation than in the non-acclimatized plants. Both parameters were higher in melatonin-treated plants than non-melatonin treated ones under cold stress (Figure 6). Parameters of quantum yields and efficiencies including values of $\varphi \mathrm{P}_{0}, \varphi \mathrm{R}_{0}, \varphi \mathrm{E}_{0}$, and $\gamma \mathrm{R}$ cause marked alterations in the plants with different treatments. The highest values of these four parameters were detected in the plants after melatonin treatment in the CA regime and the lowest values were found in the plants without melatonin treatment in the NA regime (Figures 7A-D). ABS/RC, TP0/RC, $\mathrm{ET}_{0} / \mathrm{RC}$, and $\mathrm{RE}_{0} / \mathrm{RC}$ values, known as parameters of specific energy fluxes, also changed remarkably after different treatments. In both of CA and NA regimes, these parameters decreased in the melatonintreated plants compared to those in non-treated regimes

TABLE 1 | Basic photosynthetic parameters extracted from the OJIP transient curves.

\begin{tabular}{|c|c|c|c|c|c|c|}
\hline Treatment & $F_{0}$ & $F_{M}$ & $F_{K}$ & $F_{J}$ & $F_{I}$ & $M_{0}$ \\
\hline NT & $0.28 \pm 0.004 c$ & $1.07 \pm 0.003 a$ & $0.73 \pm 0.01 a$ & $0.76 \pm 0.02 a$ & $0.97 \pm 0.01 a$ & $2.28 \pm 0.07 a$ \\
\hline $\mathrm{NT}+\mathrm{MLT}$ & $0.28 \pm 0.006 c$ & $1.07 \pm 0.005 a$ & $0.73 \pm 0.004 a$ & $0.76 \pm 0.01 a$ & $0.97 \pm 0.012 a$ & $2.34 \pm 0.09 a$ \\
\hline $\mathrm{NA}+\mathrm{MLT}$ & $0.30 \pm 0.01 b$ & $0.67 \pm 0.08 c^{*}$ & $0.46 \pm 0.04 c^{*}$ & $0.54 \pm 0.04 c^{*}$ & $0.62 \pm 0.07 c$ & $1.62 \pm 0.071 b^{*}$ \\
\hline $\mathrm{CA}$ & $0.33 \pm 0.02 \mathrm{a}$ & $0.73 \pm 0.02 b$ & $0.50 \pm 0.01 b$ & $0.55 \pm 0.01 b$ & $0.62 \pm 0.03 b$ & $1.57 \pm 0.009 b$ \\
\hline
\end{tabular}

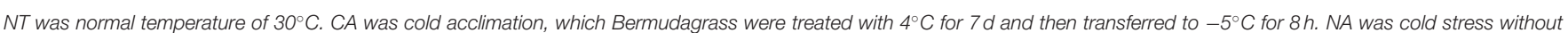
acclimation, which plants were treated with $-5^{\circ} \mathrm{C}$ for $8 \mathrm{~h}$ without pre-treatment with $4^{\circ} \mathrm{C}$. MLT was melatonin. Independent-samples $t$-test was used to determine statistical differences. Different letters indicate statistical difference significance at $P<0.05$ among the temperature treatments. Asterisk was significantly different after MLT treatment. 

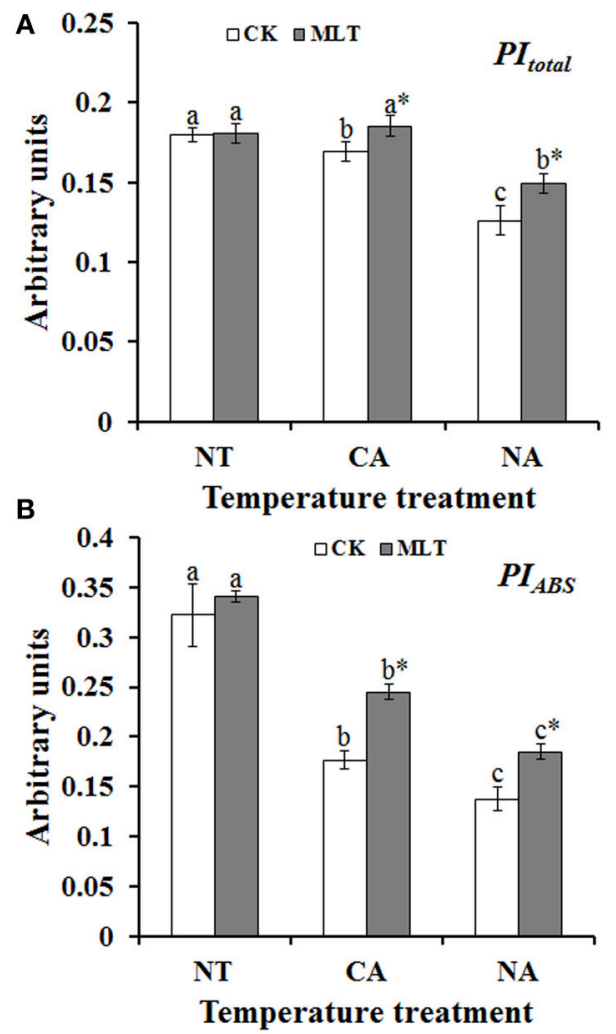

FIGURE 6 | Alterations of performance index (PI) as deduced by JIP-test analysis of fluorescence transients. (A) Alteration of Pl for energy conservation from exciton to the reduction of PSI end acceptors (P/Total). (B) Alterations of PI for energy conservation from exciton to the reduction of intersystem electron $\left(\mathrm{Pl}_{A B S}\right)$. Experiment included five repeats of each treatment, and means were average values of the data. Calculations of each parameter refer to the method of Yusuf et al. (2010). Independent-samples $t$-test was used to determine statistical differences. Bars show standard deviation. Different letters indicate statistical difference significance at $P<0.05$ among the treatments. Column marked with asterisk was significantly different after MLT treatment. NT was normal temperature of $30^{\circ} \mathrm{C}$. CA was cold acclimation, in which Bermudagrass were treated with $4^{\circ} \mathrm{C}$ for $7 \mathrm{~d}$ and then transferred to $-5^{\circ} \mathrm{C}$ for $8 \mathrm{~h}$. NA was cold stress without acclimation, which plants were treated with $-5^{\circ} \mathrm{C}$ for $8 \mathrm{~h}$ without pre-treatment with $4^{\circ} \mathrm{C}$. CK was control (treated without melatonin). MLT, melatonin.

(Figures 7E-H). ABS/RC, TP0/RC, $\mathrm{ET}_{0} / \mathrm{RC}$, and $\mathrm{RE}_{0} / \mathrm{RC}$ had the highest values in the plants that were treated without melatonin or cold acclimation, and the lowest values in the melatonin and cold acclimation-treated plants (Figures 7E-H).

To investigate metabolic homeostasis induced by exogenous melatonin treatment under cold stress, GC-MS was applied to identify the metabolites. Forty-six metabolites including 9 amino acids, 14 organic acids, 16 sugars, 4 sugar alcohols, 2 alkanes, and 1 ketone were detected in all different treatments (Figure 8, Table 2). Generally, under cold stress, there were alterations in metabolite concentrations after melatonin application. This alteration was less in NA regime than that of CA regime. Dramatic changes in metabolite levels were observed in the CA regime plants, and a large proportion of them showed higher concentrations in the melatonin-treated plants than in controls
(Figure 8, Table 2). Among the various metabolites, 5 sugars (arabinose, mannose, glucopyranose, maltose, and turanose) and 1 organic acid (propanoic acid) increased significantly in melatonin-pretreated plants under both of NA and CA treatment (Table 2). PCA of the 46 metabolites separated clearly between different conditions (Supplemental Figures S1, S2). Specifically, after cold treatment, the first principal component, designated as $\mathrm{PC} 1$, separated the $\mathrm{CA}$ regime from NA regime clearly, which was represented $37 \%$ of the total variance. In the second dimension, PC2 separated the melatonin treatment from nonmelatonin treatment clearly, which represented $22.2 \%$ of the total variance (Supplemental Figure S2). These results suggested that exogenous melatonin affects the principal metabolites under cold stress especially in Bermudagrass after cold acclimation.

\section{DISCUSSION}

Cold is a key factor that limits resource utilization of Bermudagrass. Thus, finding a way of improving cold resistance of this species is important for turf industry (Chen et al., 2015). Nitric oxide and jasmonic acid were reported to improve plant cold resistance (Cheong and Choi, 2003; Cantrel et al., 2011; Fan et al., 2015). Recently, melatonin was reported to have positive functions in protecting plants against biotic and abiotic stress (Li et al., 2012; Bajwa et al., 2014; Meng et al., 2014; Lee et al., 2015; Reiter et al., 2015; Zhao et al., 2015; Shi et al., 2015b). However, the mechanisms of melatonin involvement in cold stress response in Bermudagrass are largely unknown. Here (phenotypic change, Supplemental Figure S3), physiological alterations, the process of photosystem II and changes in metabolism in pre-cold acclimated and non-cold acclimated Bermudagrass under freezing stress after melatonin treatment were investigated.

Cell membrane stability was assessed as an indicator of cellular damage induced by multiple abiotic stresses (Saneoka et al., 2004). Cell membrane systems were also the major sites of cold injury in plants (Steponkus, 1984). Lipid peroxidation and plasma membrane injury is induced by cold stress in many plants including Bermudagrass (Zhang et al., 2006). In the current study, the results showed that both of EL and MDA contents were lower in melatonin-treated plants than those in non-melatonin treated regimes under cold stress, and the values were higher in NA than CA regimes (Figure 1). These results suggested that cold acclimation remarkably improves cold resistance of Bermudagrass, and that exogenous melatonin played a positive role in maintaining cell membrane stability to protecting Bermudagrass against cold stress.

Reactive oxygen species (ROS) were formed, and hence led to oxidative damage when plants were exposed to cold stress. Recently, melatonin was reported to play roles in counteracting the effects of ROS in various stresses (Fischer et al., 2004; Posmyk and Janas, 2009; Shi et al., 2015b). In the present study, the results revealed that melatonin played a crucial role in cold resistance of Bermudagrass. Melatonin is an antioxidant that scavenges radicals directly and indirectly that exists extensively in animals and plants (Tan et al., 1993; Posmyk and Janas, 2009; Zhang and Zhang, 2014). The exogenous application of melatonin 


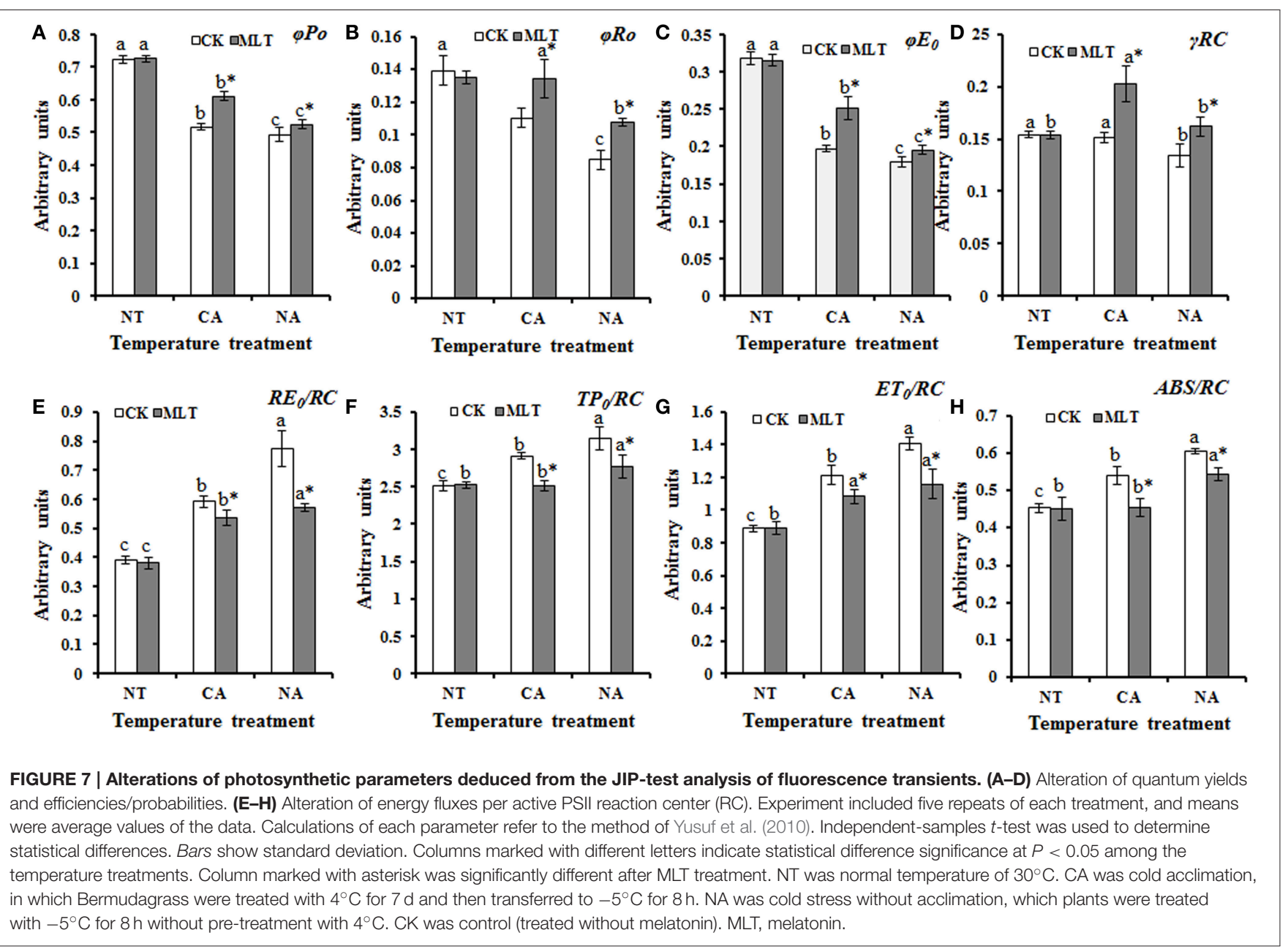

in the plants of the two regimes (CA and NA) dramatically activated antioxidant enzymes POD and SOD. Interestingly, the antioxidant enzyme activities were higher in the NA regime than that in CA regime (Figure 3). This might be attributed to the sudden drastic reduction of the temperature, and induction of the excessive generation of ROS in the plants. To scavenge ROS, antioxidant enzymes activities, like POD and SOD were increased in the plants. In addition, exogenous melatonin improved the activities further. It was reported that under oxidative stress, ROS generation increases antioxidant enzymes activities in plants (Yan et al., 2010; Fan et al., 2014). The results suggested that exogenously-applied melatonin stimulates antioxidant enzymes activities in Bermudagrass under cold stress, and thus enhanced plant cold resistance.

When plants were exposed to cold stress, chlorophyll was degraded thereby the leaves experienced chlorosis (Koç et al., 2010). Chlorophyll content of the leaves provides vital information about the physiological condition of the plants (Gitelson et al., 2003). In this study, chlorophyll content was higher in melatonin treated plants than that in non-melatonin treated regimes under cold stress (Figures $4 \mathbf{A}-\mathbf{C}$ ). The ratio of chlorophyll $a$ to $b(\mathrm{chl}-a / b)$ is a valuable measurement of the proportion of LHCII (light-harvesting complex associated with PSII) to other components that contain chlorophyll (Leong and Anderson, 1984). As the results indicated, chl- $a / b$ was significantly higher in melatonin treated plants than that in control. Moreover, cold acclimation increased this ratio. As shown in the Figure $4 \mathrm{D}$, the value of chl- $a / b$ in $\mathrm{CA}$ regime was higher than that in NA regime. These results showed that exogenous melatonin protects chlorophyll from degradation and then improves cold resistance and photosynthetic efficiency of Bermudagrass under cold stress.

Chlorophyll $a$ fluorescence has been broadly employed in studying photosystem especially under abiotic stress conditions (Chen et al., 2013; Roopin et al., 2013). To further explore the behavior of PSII of Bermudagrass under cold stress, chlorophyll a fluorescence analysis including OJIP curve and JIP-test were applied. Alteration of the curves implied that exogenous melatonin was crucial in Bermudagrass cold stress resistance regardless of cold acclimation or no acclimation (Figure 5). Abundant information was revealed by the OJIP fluorescence transient, and it was used to determine the parameters by JIPtest that quantified the energy flow through PSII at the level of reaction center (RC) (Strasser and Strasser, 1995) (Table 3). 


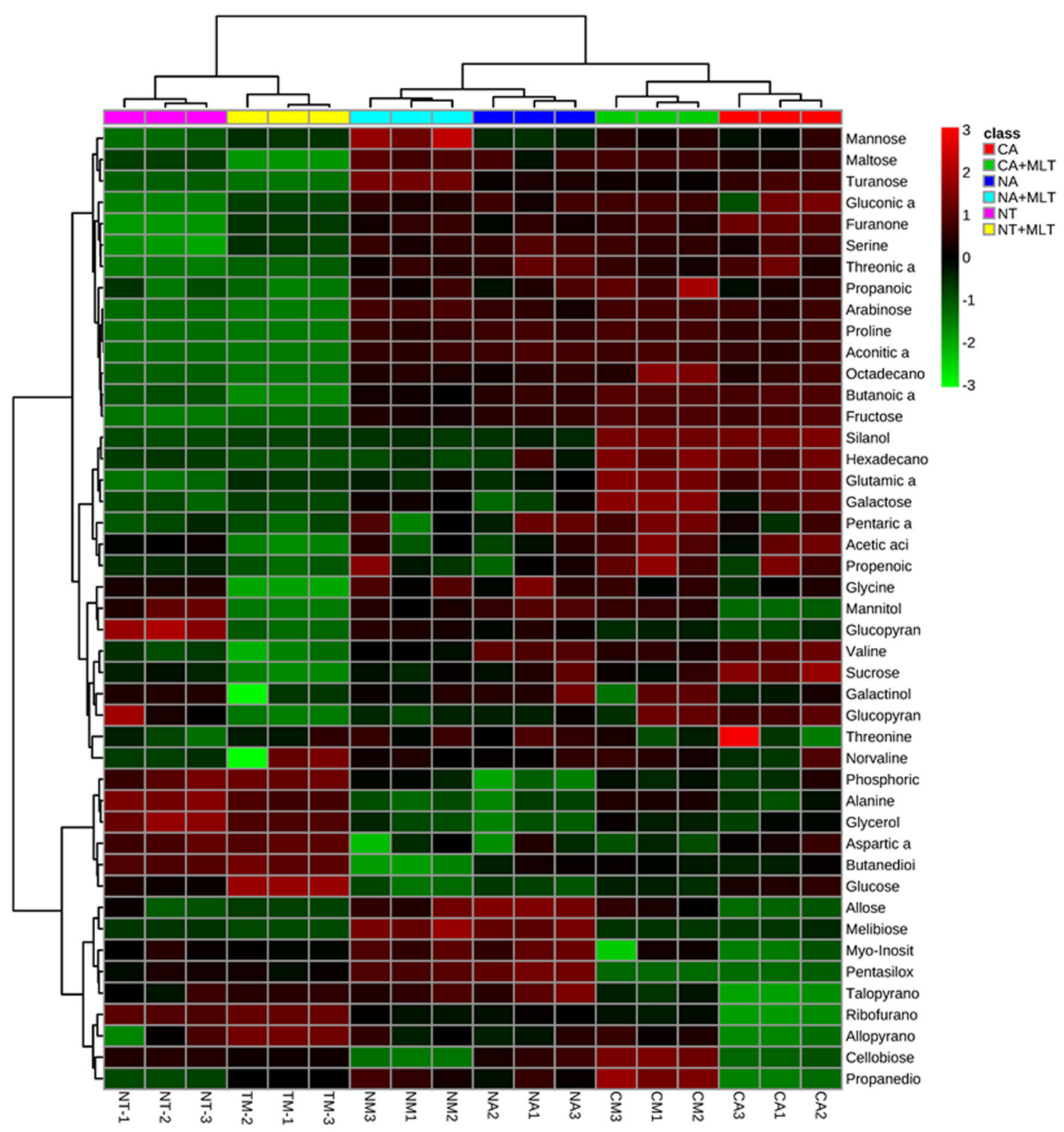

FIGURE 8 | Hierarchical cluster analysis of 46 metabolites modulated by $100 \mu \mathrm{M}$ melatonin in leaves of Bermudagrassunder cold stress. NT was normal temperature of $30^{\circ} \mathrm{C}$. CA was cold acclimation, in which Bermudagrass was treated with $4^{\circ} \mathrm{C}$ for $7 \mathrm{~d}$ and then transferred to $-5^{\circ} \mathrm{C}$ for $8 \mathrm{~h}$. NA was cold stress without acclimation, in which plants were treated with $-5^{\circ} \mathrm{C}$ for $8 \mathrm{~h}$ without pre-treatment with $4^{\circ} \mathrm{C}$. MLT, melatonin. The heatmap was performed on the website of http:// www.metaboanalyst.ca/MetaboAnalyst/.

For the $F_{0}$ value, the minimal recorded fluorescence intensity, no significant difference was found in the plants treated with or without melatonin in the two regimes CA and NA. However, the $F_{\mathrm{M}}$ values were higher in the plants after melatonin treatment than those in non-melatonin treatment regimes. Similar changes of other basic parameters including $F_{\mathrm{J}}, F_{\mathrm{I}}$, and $M_{0}$ were observed. This suggests that exogenous melatonin was involved in cold resistance of Bermudagrass (Table 1). The performance index (PI), was a sensitive parameter of JIP-test that evaluates the photochemical activities under stress condition. It combines three primary functional steps containing light energy absorption step, excitation energy trapping step, and conversion of excitation energy to electron transport step. This suggested photosynthetic activity through a reaction center complex of PSII into a single multi-parametric expression (Strasser et al., 1999). In the present study, the observation that $\mathrm{PI}_{\text {total }}$ (overall behavior of the photosynthetic activities) and $\mathrm{PI}_{\mathrm{ABS}}$ (density of RC that is expressed per absorption) were higher in the melatonin-treated plants than the non-treated regimes (Figure 6), implied that exogenous melatonin plays a protective role in cold resistance 
TABLE 2 | Forty six metabolites in leaves of bermudagrass under cold stress.

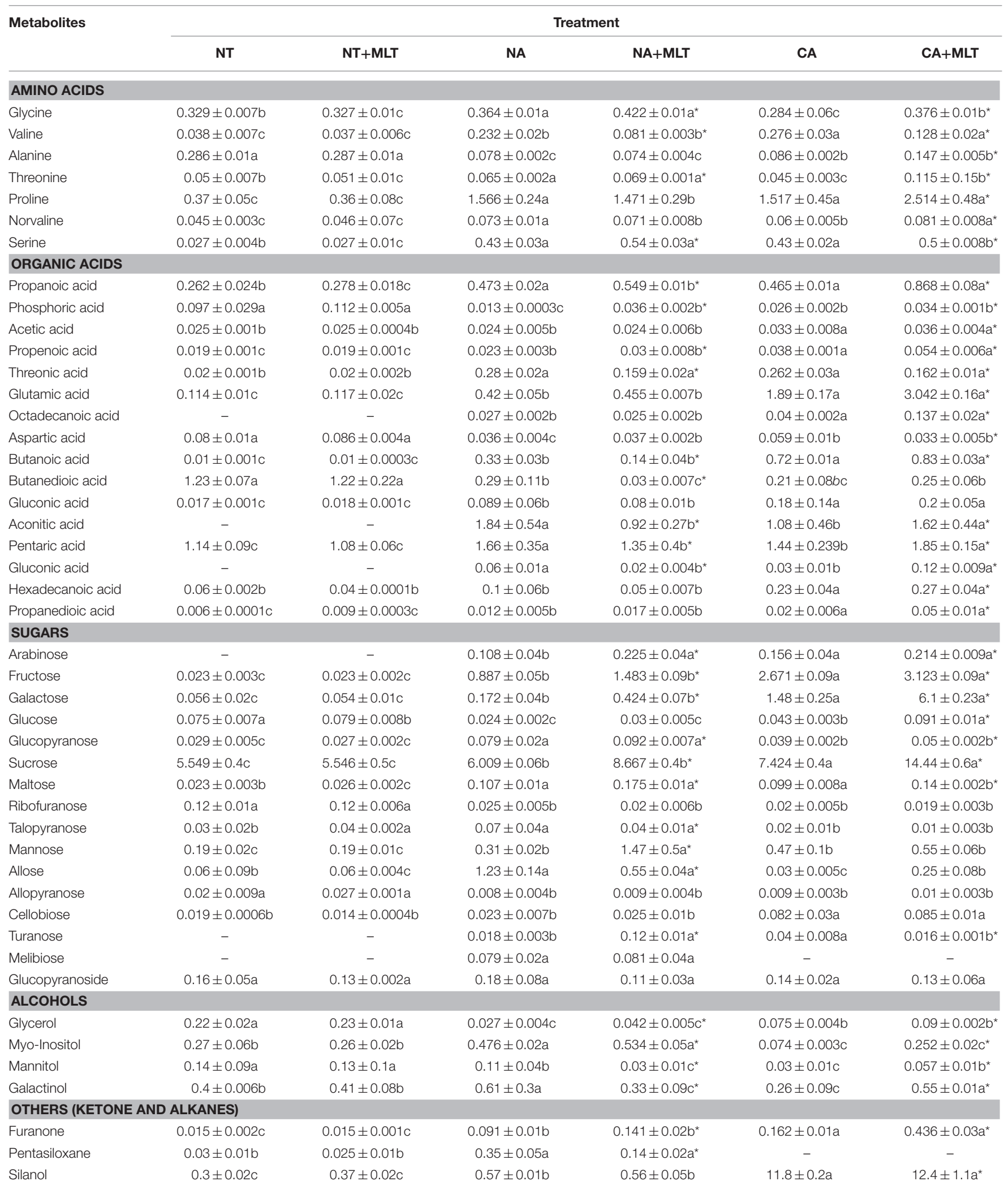

NT was normal temperature of $30^{\circ} \mathrm{C}$. CA was cold acclimation, which Bermudagrass were treated with $4^{\circ} \mathrm{C}$ for $7 d$ and then transferred to $-5^{\circ} \mathrm{C}$ for $8 \mathrm{~h}$. NA was cold stress without acclimation, which plants were treated with $-5^{\circ} \mathrm{C}$ for $8 \mathrm{~h}$ without pre-treatment with $4^{\circ} \mathrm{C}$. MLT was melatonin. Statistical analysis was performed by One-way analysis of variance (ANOVA). Means were separated with Duncan's multiple range tests at a significant level of $P<0.05$. Different letters indicate statistical difference significance at $P<0.05$ among the temperature treatments. Asterisk was significantly different after MLT treatment. 
TABLE 3 | Definitions of the photosynthetic parameters deduced by the JIP-test analysis for the analysis of $\mathrm{Chl}$ a fluorescence transient.

Data extracted from the recorded $\mathrm{Chl}$ a fluorescence transient OJIP curve

\begin{tabular}{ll}
\hline$F_{O}=F_{20 \mu \mathrm{s}}$ & Minimal reliable recorded fluorescence \\
$F_{K}=F_{300 \mu \mathrm{s}}$ & Fluorescence intensity at $300 \mu \mathrm{s}$ \\
$F_{J}=2.97 \mathrm{~ms}$ & $\begin{array}{l}\text { Fluorescence intensity at J step }(2.97 \mathrm{~ms}) \text { of OJIP } \\
\text { curve }\end{array}$ \\
$F_{I}=62 \mathrm{~ms}$ & $\begin{array}{l}\text { Fluorescence intensity at I step (62 ms) of OJIP } \\
\text { curve }\end{array}$ \\
$F_{P}=F_{M}$ & Fluorescence intensity at the peak of OJIP curve \\
\hline
\end{tabular}

Performance indexes (partial potentials at the steps of energy bifurcations)

\begin{tabular}{ll}
\hline $\mathrm{PI}_{\text {ABS }}$ & $\begin{array}{l}\text { Performance index for energy conservation from } \\
\text { exciton to the reduction of intersystem electron } \\
\text { acceptors }\end{array}$ \\
$\mathrm{PI}_{\text {total }}$ & $\begin{array}{l}\text { Performance index for energy conservation from } \\
\text { exciton to the reduction of photosystem I end } \\
\text { acceptors }\end{array}$
\end{tabular}

Quantum yields and efficiencies/probabilities

\begin{tabular}{ll}
\hline$\varphi \mathrm{PO}$ & $\begin{array}{l}\text { Maximum quantum yield for primary photochemistry } \\
\left(F_{V} / F_{M}\right)\end{array}$ \\
$\varphi_{\mathrm{RO} O}$ & $\begin{array}{l}\text { Quantum yield for reduction of end electron } \\
\text { acceptors at the PSI acceptor side (RE) }\end{array}$ \\
$\varphi_{\mathrm{E} O}$ & Quantum yield for electron transport (ET) \\
$\gamma_{\mathrm{RC}}$ & Probability that a PSIl Chl molecule functions as RC \\
\hline
\end{tabular}

Specific energy fluxes (per $Q_{A}^{-}$reducing PSII reaction center-RC)

\begin{tabular}{ll}
\hline $\mathrm{RE}_{0} / \mathrm{RC}$ & Electron flux reducing end electron acceptors at the \\
& $\mathrm{PS}$ acceptor side, per $\mathrm{RC}$ \\
$\mathrm{TP}_{0} / \mathrm{RC}$ & Trapping flux (leading to $\mathrm{Q}_{A}$ reduction) per $\mathrm{RC}$ \\
$\mathrm{ET} \mathrm{T}_{0} / \mathrm{RC}$ & Electron transport flux (further than $\mathrm{Q}_{A}^{-}$) per $\mathrm{RC}$ \\
$\mathrm{ABS} / \mathrm{RC}$ & Absorption flux (of antenna Chls) per $\mathrm{RC}$
\end{tabular}

of Bermudagrass. $\varphi \mathrm{P}_{0}$, the maximum quantum yield for primary photochemistry, was strongly improved by melatonin in Bermudagrass under cold stress (Figure 7A). Similar results were also detected in the values of $\varphi \mathrm{E}_{0}$ (quantum yield of the electron transport flux from $\mathrm{Q}_{A}$ to $\mathrm{Q}_{B}$ ), $\varphi \mathrm{R}_{0}$ (quantum yield for reduction of end electron acceptors at the PSI acceptor side), and $\gamma \mathrm{RC}$ (probability that a molecule of PSII Chl functions as RC) (Figures 7B-D). This suggests that melatonin influences the quantum yield on the sides of donor and acceptor of PSII. For the analysis of functional properties of PSII, parameters of specific energy fluxes such as $\mathrm{ABS} / \mathrm{RC}, \mathrm{TP}_{0} / \mathrm{RC}, \mathrm{ET}_{0} / \mathrm{RC}$, and $\mathrm{RE}_{0} / \mathrm{RC}$ were analyzed. The behavior of Bermudagrass leaves was altered dramatically after the melatonin treatment, suggesting a distinct effect of exogenous melatonin on the RC (Figures 7E-H). Exogenous melatonin alleviated the negative effects of cold on RC and increased the quantity of RC under cold stress.

Alterations of photosynthesis could lead to the change of metabolites components. Previous studies reported that metabolism dramatically changes under multiple stresses and senescence processes (Wang et al., 2014; Shi et al., 2015b). To further investigate whether melatonin modulates metabolic homeostasis, GC-MS was employed. As the results showed, almost all of the examined metabolites exhibited higher concentrations in the plants treated with melatonin than that of control (Figure 8, Table 2). Among the enhanced metabolites, carbohydrates such as fructose, galactose, glucose, and sucrose as well as proline have been reported to be crucial components for osmotic adaptation in abiotic stress response. This implies that melatonin may be involved in modulating synthesis of these metabolites to improve cold resistance (Krasensky and Jonak, 2012). Moreover, other metabolites including various carbohydrates, organic acids, and amino acids also increased in melatonin-treated plants. These results indicated that melatonin had comprehensive effects on multiple metabolic pathways, and these metabolic changes might be involved in cold resistance of Bermudagrass. Five sugars (arabinose, mannose, glucopyranose, maltose, and turanose) and one organic acid (propanoic acid) were significantly increased. However, valine and threonic acid contents were found to be decreased in melatonin-treated plants (Table 2), and hence roles of these metabolites in Bermudagrass response to cold need to be further investigated.

In summary, our findings reveal that melatonin plays a positive role in Bermudagrass to protect against cold stress in cold and non-cold acclimation conditions. This provides evidence that melatonin participates in cold stress through modulating photosynthesis and metabolism related pathways.

\section{AUTHOR CONTRIBUTIONS}

JF and LC designed research; $\mathrm{ZH}$ and JF performed the experiments, analyzed the data and wrote the manuscript; YX analyzed the data of metabolism; EA, LC, ZC, and JF revised the manuscript. All authors declare no competing financial interests.

\section{ACKNOWLEDGMENTS}

This work was supported by the China National Science Foundation (NSFC) (Grant Nos. 31401915 and 31272194), China-Africa Center for Research and Education (Grant No. SAJC201325), the Hubei Province National Science Foundation Sciences (Grant No. ZRY1326) and the outstanding young talent program of CAS Key Laboratory of Plant Germplasm Enhancement and Specialty Agriculture (Grant No. Y452341X01). We would like to thank Lipeng Zhou for collecting the documents.

\section{SUPPLEMENTARY MATERIAL}

The Supplementary Material for this article can be found online at: http://journal.frontiersin.org/article/10.3389/fpls.2015. 00925 


\section{Supplemental Figure S1 | Principal Component analysis (PCA) of the} metabolite profiles in bermudagrass under control conditions and cold stress. NT was normal temperature of $30^{\circ} \mathrm{C}$. CA was cold acclimation, which bermudagrass were treated with $4^{\circ} \mathrm{C}$ for $7 \mathrm{~d}$ and then transferred to $-5^{\circ} \mathrm{C}$ for $8 \mathrm{~h}$. NA was cold stress without acclimation, which plants were treated with $-5^{\circ} \mathrm{C}$ for $8 \mathrm{~h}$ without pre-treatment with $4^{\circ} \mathrm{C}$. MLT, melatonin.

Supplemental Figure S2 | Principal Component analysis (PCA) of the metabolite profiles in bermudagrass under cold stress. NT was normal temperature of $30^{\circ} \mathrm{C}$. CA was cold acclimation, in which Bermudagrass was

\section{REFERENCES}

Allen, D. J., and Ort, D. R. (2001). Impacts of chilling temperatures on photosynthesis in warm-climate plants. Trends Plant Sci. 6, 36-42. doi: 10.1016/S1360-1385(00)01808-2

Allen, R. D. (1995). Dissection of oxidative stress tolerance using transgenic plants. Plant Physiol. 107, 1049-1054.

Ao, P., Li, Z., and Fan, D. (2013). Involvement of antioxidant defense system in chill hardening-induced chilling tolerance in Jatropha curcas seedlings. Acta Physiol. Plant. 35, 153-160. doi: 10.1007/s11738-012-1058-z

Arnao, M. B., and Hernández-Ruiz, J. (2015). Functions of melatonin in plants. J. Pineal Res. 59, 133-150. doi: 10.1111/jpi.12253

Baek, K. H., and Skinner, D. Z. (2003). Alteration of antioxidant enzyme gene expression during cold acclimation of near-isogenic wheat lines. Plant Sci. 165, 1221-1227. doi: 10.1016/S0168-9452(03)00329-7

Bajwa, V. S., Shukla, M. R., Sherif, S. M., Murch, S. J., and Saxena, P. K. (2014). Role of melatonin in alleviating cold stress in Arabidopsis thaliana. J. Pineal Res. 56:238-245. doi: 10.1111/jpi.12115

Cantrel, C., Vazquez, T., Puyaubert, J., Rezé, N., Lesch, M., Kaiser, W. M., et al. (2011). Nitric oxide participates in cold-responsive phosphosphingo lipid formation and gene expression in Arabidopsis thaliana. New Phytol. 189, 415-427. doi: 10.1111/j.1469-8137.2010.03500.x

Chen, K., Chen, L., Fan, J., and Fu, J. (2013). Alleviation of heat damage to photosystem II by nitric oxide in tall fescue. Photosynth. Res. 116, 21-31. doi: 10.1007/s11120-013-9883-5

Chen, L., Fan, J., Hu, L., Hu, Z., Xie, Y., Zhang, Y., et al. (2015). A transcriptomic analysis of bermudagrass (Cynodon dactylon) provides novel insights into the basis of low temperature tolerance. BMC Plant Biol. 15, 216. doi: 10.1186/s12870-015-0598-y

Chen, Q., Qi, W. B., Reiter, R. J., Wei, W., and Wang, B. M. (2009). Exogenously applied melatonin stimulates root growth and raises endogenous indoleacetic acid in roots of etiolated seedlings of Brassica juncea. J. Plant. Physiol. 166, 324-328. doi: 10.1016/j.jplph.2008.06.002

Chen, T. H., and Murata, N. (2002). Enhancement of tolerance of abiotic stress by metabolic engineering of betaines and other compatible solutes. Curr. Opin. Plant Biol. 5, 250-257. doi: 10.1016/S1369-5266(02)00255-8

Cheong, J. J., and Choi, Y. D. (2003). Methyl jasmonate as a vital substance in plants. Trends Genet. 19, 409-413. doi: 10.1016/S0168-9525(03)00138-0

Cook, D., Fowler, S., Fiehn, O., and Thomashow, M. F. (2004). A prominent role for the $\mathrm{CBF}$ cold response pathway in configuring the low temperature metabolome of Arabidopsis. Proc. Natl. Acad. Sci., USA. 101, 15243-15248. doi: 10.1073/pnas.0406069101

Dahal, K., Kane, K., Gadapati, W., Webb, E., Savitch, L. V., Singh, J., et al. (2012). The effects of phenotypic plasticity on photosynthetic performance in winter rye, winter wheat, and Brassica napus. Physiol. Plant. 144, 169-188. doi: 10.1111/j.1399-3054.2011.01513.x

Dubbels, R., Reiter, R. J., Klenke, E., Goebel, A., Schnakenberg, E., Ehlers, C., et al. (1995). Melatonin in edible plants identified by radioimmunoassay and by high performance liquid chromatography- mass spectrometry. J. Pineal Res. 18, 28-31. doi: 10.1111/j.1600-079X.1995.tb00136.x

Fan, J., Chen, K., Amombo, E., Hu, Z., Chen, L., and Fu, J. (2015). Physiological and molecular mechanism of nitric oxide (NO) involved in Bermudagrass response to cold stress. PLos ONE. 10:e0132991. doi: 10.1371/journal.pone.0132991

Fan, J., Ren, J., Zhu, W., Amombo, E., Fu, J., and Chen, L. (2014). Antioxidant responses and gene expression in bermudagrass under cold stress. J. Amer. Soc. Hort. Sci. 139, 699-705. treated with $4^{\circ} \mathrm{C}$ for $7 \mathrm{~d}$ and then transferred to $-5^{\circ} \mathrm{C}$ for $8 \mathrm{~h}$. NA was cold stress without acclimation, in which plants were treated with $-5^{\circ} \mathrm{C}$ for $8 \mathrm{~h}$ without pre-treatment with $4^{\circ} \mathrm{C}$. MLT, melatonin.

Supplemental Figure S3 | The representative leaves of the plants under different treatments. (A) The representative leaves of the plants under control condition; (B) The representative leaves of the plants under cold acclimation condition; (C) The representative leaves of the plants under non-cold acclimation condition. CK was control (treated without melatonin). MLT, melatonin; CA, cold acclimation; NA, non-cold acclimation.

Fischer, T. W., Scholz, G., Knöll, B., Hipler, U. C., and Elsner, P. (2004). Melatonin suppresses reactive oxygen species induced by UV irradiation in leukocytes. J. Pineal Res. 37, 107-112. doi: 10.1111/j.1600-079X.2004.00142.x

Fracheboud, Y., Haldimann, P., Leipner, J., and Stamp, P. (1999). Chlorophyll fluorescence as a selection tool for cold tolerance of photosynthesis in maize (Zea mays L.). J. Exp. Bot. 50, 1533-1540. doi: 10.1093/jxb/50.338.1533

Gitelson, A. A., Gritz, Y., and Merzlyak, M. N. (2003). Relationships between leaf chlorophyll content and spectral reflectance and algorithms for non-destructive chlorophyll assessment in higher plant leaves. J. Plant Physiol. 160, 271-282. doi: 10.1078/0176-1617-00887

Hernández-Ruiz, J., Cano, A., and Arnao, M. B. (2004). Melatonin: a growthstimulating compound present in lupin tissues. Planta. 220, 140-144. doi: $10.1007 / \mathrm{s} 00425-004-1317-3$

Hiscox, J., and Israelstam, G. (1979). A method for the extraction of chlorophyll from leaf tissue without maceration. Can. J. Bot. 57, 1332-1334. doi: $10.1139 / \mathrm{b} 79-163$

Hoagland, D. R., and Arnon, D. I. (1950). The water-culture method for growing plants without soil. Calif. Agr. Expt. Stat. Circ. 347.

Hou, Y., Guo, Z., Yi, Y., Li, H., Li, H., Chen, L., et al. (2010). Effects of cold acclimation and exogenous phytohormone abscisic acid treatment on physiological indicators of winterness wheat. J. Plant. Sci. 5, 125-136. doi: 10.3923/jps.2010.125.136

Hu, L., Li, H., Pang, H., and Fu, J. (2012). Responses of antioxidant gene, protein and enzymes to salinity stress in two genotypes of perennial ryegrass (Lolium perenne) differing in salt tolerance. J. Plant Physiol. 169, 146-156. doi: 10.1016/j.jplph.2011.08.020

Koç, E., İşlek, C., and Üstün, A. S. (2010). Effect of cold on protein, proline, phenolic compounds and chlorophyll content of two pepper (Capsicum annuum L.) varieties. Gazi Univer. J. Sci. 23, 1-6.

Kolář, J., Macháčková, I., Eder, J., Prinsen, E., Van Dongen, W., Van Onckelen, H., et al. (1997). Melatonin: occurrence and daily rhythm in Chenopodium rubrum. Phytochemistry. 44, 1407-1413. doi: 10.1016/S0031-9422(96)00568-7

Krasensky, J., and Jonak, C. (2012). Drought, salt, and temperature stress-induced metabolic rearrangements and regulatory networks. J. Exp. Bot. 63, 1593-1608. doi: 10.1093/jxb/err460

Lee, H. Y., Byeon, Y., Tan, D. X., Reiter, R. J., and Back, K. (2015). Arabidopsis serotonin $\mathrm{N}$-acetyltransferase knockout mutant plants exhibit decreased melatonin and salicylic acid levels resulting in susceptibility to an avirulent pathogen. J. Pineal Res. 58:291-299. doi: 10.1111/jpi.12214

Leong, T. Y., and Anderson, J. M. (1984). Adaptation of the thylakoid membranes of pea chloroplasts to light intensities. II. Regulation of electron transport capacities, electron carriers, coupling factor $\left(\mathrm{CF}_{1}\right)$ activity and rates of photosynthesis. Photosynth. Res. 5, 117-128. doi: 10.1007/BF00028525

Li, C., Wang, P., Wei, Z., Liang, D., Liu, C., Yin, L., et al. (2012). The mitigation effects of exogenous melatonin on salinity-induced stress in Malus hupehensis. J. Pineal Res. 53, 298-306. doi: 10.1111/j.1600-079X.2012.00999.x

Manchester, L. C., Tan, D. X., Reiter, R. J., Park, W., Monis, K., and Qi, W. (2000). High levels of melatonin in the seeds of edible plants possible function in germ tissue protection. Life Sci. 67, 3023-3029. doi: 10.1016/S0024-3205(00)00896-1

Meng, J. F., Xu, T. F., Wang, Z. Z., Fang, Y. L., Xi, Z. M., and Zhang, Z. W. (2014). The ameliorative effects of exogenous melatonin on grape cuttings under water-deficient stress: antioxidant metabolites, leaf anatomy, and chloroplast morphology. J. Pineal Res. 57, 200-212. doi: 10.1111/jpi.12159

Monk, L. S., Fagerstedt, K. V., and Crawford, R. M. M. (1989). Oxygen toxicity and superoxide dismutase as an antioxidant in physiological stress. Physiol. Plant. 76, 456-459. doi: 10.1111/j.1399-3054.1989.tb06219.x 
Murch, S. J., Campbell, S. S. B., and Saxena, P. K. (2001). The role of serotonin and melatonin in plant morphogenesis: regulation of auxin-induced root organogenesis in in vitro-cultured explants of St. John's wort (Hypericum perforatum L.). In Vitro Cell Dev. Biol. Plant. 37, 786-793. doi: 10.1007/s11627001-0130-y

Murch, S. J., and Saxena, P. K. (2002). Mammalian neurohormones: potential significance in reproductive physiology of St. John's wort (Hypericum perforatum L.)? Naturwissenschaften 89, 555-560. doi: 10.1007/s00114-0020376-1

Murch, S. J., Simmons, C. B., and Saxena, P. K. (1997). Melatonin in feverfew and other medical plants. Lancet 350, 1598-1599. doi: 10.1016/S01406736(05)64014-7

Pelagio-Flores, R., Muñoz-Parra, E., Ortiz-Castro, R., and López-Bucio, J. (2012). Melatonin regulates Arabidopsis root system architecture likely acting independently of auxin signaling. J. Pineal Res. 53, 279-28819. doi: 10.1111/j.1600-079X.2012.00996.X

Posmyk, M. M., and Janas, K. M. (2009). Melatonin in plants. Acta Physiol. Plant. 31, 1-11. doi: 10.1007/s11738-008-0213-Z

Reiter, R. J., Tan, D. X., and Galano, A. (2014). Melatonin: exceeding expectations. Physiology (Besthesda). 29, 325-333. doi: 10.1152/physiol.00011.2014

Reiter, R. J., Tan, D. X., Zhou, Z., Cruz, M. H. C., Fuentes-Broto, L., and Galano, A. (2015). Phytomelatonin: assisting plants of survive and thrive. Molecules. 20, 7396-7437. doi: 10.3390/molecules20047396

Rizza, F., Pagani, D., Stanca, A. M., and Cattivelli, L. (2001). Use of chlorophyll fluorescence to evaluate the cold acclimation and freezing tolerance of winter and spring oats. Plant Breed. 120, 389-396. doi: 10.1046/j.14390523.2001.00635.X

Roopin, M., Yacobi, Y. Z., and Levy, O. (2013). Occurrence, diel patterns, and the influence of melatonin on the photosynthetic performance of cultured Symbiodinium. J. Pineal Res. 55, 89-100. doi: 10.1111/jpi.12046

Saneoka, H., Moghaieb, R. E. A., Premachandra, G. S., and Fujita, K. (2004). Nitrogen nutrition and water stress effects on cell membrane stability and leaf water relations in Agrostis palustris Huds. Environ. Exp. Bot. 52, 131-138. doi: 10.1016/j.envexpbot.2004.01.011

Shi, H., Chen, Y., Tan, D. X., Reiter, R. J., Chan, Z., and He, C. (2015a). Melatonin induces nitric oxide and the potential mechanisms relate to innate immunity against bacterial pathogen infection in Arabidopsis. J. Pineal Res. 59, 102-108. doi: $10.1111 /$ jpi.12244

Shi, H., Jiang, C., Ye, T., Tan, D. X., Reiter, R. J., Zhang, H., et al. (2015b). Comparative physiological, metabolomic, and transcriptomic analyses reveal mechanisms of improved abiotic stress resistance in Bermudagrass [Cynodon dactylon (L). Pers.] by exogenous melatonin. J. Exp. Bot. 66, 681-694. doi: 10.1093/jxb/eru373

Shi, H., Reiter, R. J., Tan, D. X., and Chan, Z. (2015c). INDOLE-3-ACETIC ACID INDUCIBLE 17 positively modulates natural leaf senescence through melatonin-mediated pathway in Arabidopsis. J. Pineal Res. 58, 26-33. doi: 10.1111/jpi.12188

Shi, H., Tan, D. X., Reiter, R. J., Ye, T., Yang, F., and Chan, Z. (2015d). Melatonin induces class A1 heat-shock factors (HSFA1s) and their possible involvement of thermotolerance in Arabidopsis. J. Pineal Res. 58, 335-342. doi: 10.1111/jpi.12219

Shi, H., Wang, X., Tan, D. X., Reiter, R. J., and Chan, Z. (2015e). Comparative physiological and proteomic analyses reveal the actions of melatonin in the reduction of oxidative stress in Bermudagrass (Cynodon dactylon (L). Pers.). J. Pineal Res. doi: 10.1111/jpi.12246

Steponkus, P. L. (1984). Role of the plasma membrane in freezing injury and cold acclimation. Annu. Rev. Plant. Physiol. 35, 543-584. doi: 10.1146/annurev.pp.35.060184.002551

Stitt, M., and Hurry, V. A. (2002). Plant for all seasons: alterations in photosynthetic carbon metabolism during cold acclimation in Arabidopsis. Curr. Opin. Plant Biol. 5, 199-206. doi: 10.1016/S1369-5266(02)00258-3

Strasser, B. J., and Strasser, R. J. (1995). "Measuring fast fluorescence transients to address environmental questions: the JIP-test," in Photosynthesis: from Light to Biosphere, ed P. Mathis (Dordrecht: Kluwer Academic Publishers Press), 977-980.

Strasser, R. J., Srivastava, A., and Tsimilli-Michael, M. (1999). "Screening the vitality and photosynthetic activity of plants by the fluorescence transient," in Crop Improvement for Food Security, eds R. K. Behl, M. S. Punia, and B. P. S. Lather (Hisar: SSARM Press), 60-71.

Strauss, A. J., Krüger, G. H. J., Strasser, R. J., and Heerden, P. D. R. (2006). Ranking of dark chilling tolerance in soybean genotypes probed by the chlorophyll a fluorescence transient O-J-I-P. Environ. Exp. Bot. 56, 147-157. doi: 10.1016/j.envexpbot.2005.01.011

Tal, O., Haim, A., Harel, O., and Gerchman, Y. (2011). Melatonin as an antioxidant and its semi-lunar rhythm in green macroalga Ulva sp. J. Exp. Bot. 62, 1903-1910. doi: 10.1093/jxb/erq378

Tan, D. X., Chen, L. D., Poeggeler, B., Manchester, L. C., and Reiter, R. J. (1993). Melatonin: a potent, endogenous hydroxyl radical scavenger. Endocr. J. 1, 57-60.

Tan, D. X., Manchester, L. C., Di Mascio, P., Martinez, G. R., Prado, F. M., and Reiter, R. J. (2007). Novel rhythms in N1-acetyl-N2-formyl5-methoxykynuramine and its precursor melatonin in water hyacinth: importance for phytoremediation. FASEB J. 21, 1724-1729. doi: 10.1096/fj.06$7745 \mathrm{com}$

Wang, P., Sun, X., Xie, Y., Li, M., Chen, W., Zhang, S., et al. (2014). Melatonin regulates proteomic changes during leaf senescence in Malus hupehensis. J. Pineal Res. 57, 291-307. doi: 10.1111/jpi.12169

Xie, Y., Hu, L., Du, Z., Sun, X., Amombo, E., Fan, J., et al. (2014). Effects of cadmium exposure on growth and metabolic profile of bermudagrass [Cynodon dactylon (L.) Pers.]. PLoS ONE 9:e115279. doi: 10.1371/journal.pone. 0115279

Yan, W. W., Bai, L. P., Zhang, L., Chen, G., Fan, J. G., Gu, X. H., et al. (2010). Comparative study for cold acclimation physiological indicators of Forythia mandshurica Uyeki and Forsythia viridissima Indl. Middle-East J. Sci. Res. 6, 556-562.

Yusuf, M. A., Kumar, D., Rajwanshi, R., Strasser, R. J., Tsimilli-Michael, M., Govindjee, et al. (2010). Overexpression of gamma-tocopherol methyl transferase gene in transgenic Brassica juncea plants alleviates abiotic stress: physiological and chlorophyll $a$ fluorescence measurements. Biochim. Biophys. Acta 1797, 1428-1438. doi: 10.1016/j.bbabio.2010.02.002

Zhang, H. M., and Zhang, Y. (2014). Melatonin: a well-documented antioxidant with conditional pro-oxidant actions. J. Pineal. Res. 57, 131-146. doi: $10.1111 /$ jpi.12162

Zhang, X., Ervin, E. H., and LaBranche, A. J. (2006). Metabolic defense responses of seeded bermudagrass during acclimation to freezing stress. Crop Sci. 46, 2598-2605. doi: 10.2135/cropsci2006.02.0108

Zhao, H., Xu, L., Su, T., Jiang, Y., Hu, L., and Ma, F. (2015). Melatonin regulates carbohydrate metabolism and defenses against Pseudomonas syringaepv. tomato DC3000 infection in Arabidopsis thaliana. J. Pineal Res. 59, 109-119. doi: 10.1111/jpi.12245

Zhu, J., Dong, C. H., and Zhu, J. K. (2007). Interplay between coldresponsive gene regulation, metabolism and RNA processing during plant cold acclimation. Curr. Opin. Plant Biol. 10, 290-295. doi: 10.1016/j.pbi.2007. 04.010

Conflict of Interest Statement: The authors declare that the research was conducted in the absence of any commercial or financial relationships that could be construed as a potential conflict of interest.

Copyright (c) 2015 Fan, Hu, Xie, Chan, Chen, Amombo, Chen and Fu. This is an open-access article distributed under the terms of the Creative Commons Attribution License (CC BY). The use, distribution or reproduction in other forums is permitted, provided the original author(s) or licensor are credited and that the original publication in this journal is cited, in accordance with accepted academic practice. No use, distribution or reproduction is permitted which does not comply with these terms. 